\title{
Traumatic hemothorax: Analysis of 108 cases
}

\author{
Miktat Arif Haberal $^{a *}$, Ersin Köksal ${ }^{b}$, Murat Civan ${ }^{c}$, Kerim Tülücea, Hakan Karadağ $\breve{g}^{\mathrm{d}}$, Zeynep Şentürk Köksale \\ ${ }^{a}$ Rize State Hospital Thoracic Surgery Clinic, Rize, Turkey \\ ${ }^{b}$ Department of Anesthesiology and Reanimation, Medical Faculty, Ondokuz Mayls University, Samsun, Turkey \\ ${ }^{c}$ Rize State Hospital Cardiology Clinic, Rize, Turkey \\ ${ }^{d}$ Rize State Hospital General Surgery Clinic, Rize, Turkey \\ ${ }^{e}$ Gazi State Hospital Microbiology Laboratory, Samsun, Turkey
}

\section{ARTICLE INFO}

\section{Article History}

Received

$26 / 11 / 2012$

Accepted $\quad 09 / 01 / 2013$

\section{* Correspondence to:}

Miktat Arif Haberal

Rize State Hospital Thoracic Surgery Clinic,

Rize, Turkey

e-mail: arifhabera153@hotmail.com

\section{Keywords:}

Chest tube

Hemothorax

Thoracotomy

Trauma

\section{ABSTRACT}

To evaluate treatment approaches and follow-up results of patients with hemothorax a total of 108 patients ( 81 male and 27 female) diagnosed as hemothorax and treated between August 2006 and October 2011 were evaluated retrospectively. The most common cause of hemothorax was blunt trauma (n:92, 85.2\%) and 16 cases of hemothorax (14.8\%) had a penetrating trauma. Hemothorax after blunt trauma occured due to traffic accidents in 58 cases $(63.04 \%)$, due to falls from height in 21 cases $(22.82 \%)$, due to injuries caused by animals in 9 cases $(9.78 \%)$ and due to roadway crashes in 4 cases $(4.34 \%)$. Hemothorax after penetrating trauma, on the other hand, occured due to penetrating injuries in 10 cases $(62.5 \%)$ and due to gunshot injuries in 6 cases $(37.5 \%)$. In the present study it was found that hemothorax accompanied by other organs injury in 56 cases $(51.8 \%)$ and extremity fractures also present in 24 cases (22.2\%). Thoracotomy was performed in 14 cases and median sternotomy in one case. Mortality was detected in 5 cases (4.6\%). Hemothorax after thoracic trauma is an emergency which needs to be diagnosed immediately, inquired about accompanying organ injuries and treated accordingly.

J. Exp. Clin. Med., 2013; 30:31-33

(C) 2013 OMU

\section{Introduction}

Hemothorax is the accumulation of blood in the pleural cavity as a result of traumatic and non-traumatic (spontaneous) causes. Clinical severity of hemothorax depends on the amount, rate and etiology of bleeding into the pleural cavity, the presence of accompanying pathologies such as pneumothorax and whether it becomes chronic or not (Akay, 2002). Thoracic trauma turned out as the third most common trauma following extremity and head trauma in parallel with the current rapidly-developing technology (Cangir et al., 2000). Hemothorax is classified in terms of amount of bleeding into the thoracic cavity. Hemothorax defined as; $300 \mathrm{ml}$ or less bleeding as minimal hemothorax, 300 to $1000 \mathrm{ml}$ as medium grade hemothorax and above $1000 \mathrm{ml}$ as massive hemothorax. Majority of hemothorax cases after penetrating and blunt trauma are accompanied by other organ injuries and mortality increases in such cases, significantly (Akay, 2002; Şentürk et al., 2009; Sayır et al., 2012). In our study, diagnosis and treatment approaches of 108 cases with hemothorax were evaluated.

\section{Materials and methods}

A total of 108 patients ( 81 male and 27 female) diagnosed as hemothorax and followed up in the chest surgery clinic between August 2006 and October 2011 were evaluated retrospectively. Cases were diagnosed by two views chest X-ray, ultrasound (USG), computed tomography (CT) and thoracentesis. All cases were followed up with physical examination, blood pressure and pulse rate assessment, hemogram and biochemical tests. Blood gas measurements were also performed periodically in patients with an underlying lung pathology and unstable clinical status. In hemodynamically compromised patients, bloody thoracentesis material and even a subcutaneous amphysema were enough indications for tube thoracostomy. In these cases, 32-36 F thoracal tubes were preferably placed through $6^{\text {th }}$ or $7^{\text {th }}$ intercostal space. Thoracentesis in patients with stable vital signs was carried out after two views chest X-ray, thorax CT, hemogram and biochemical tests. This procedure was applied as USG guided in cases with low effusion. Hemothorax cases with only obliteration 
of costodiaphragmatic angles were excluded from the study. In all patients who underwent tube thoracostomy, chest tubes were clamped and chest X-rays were taken 12 hours before deciding termination of thoracostomy, when drained fluid decreased below $50 \mathrm{ml} /$ day, lung expansion was completed and drained fluid became serous. All patients were followed up for 24 hours, then chest X-rays taken and discharged. Thoracotomy indications after tube thoracostomy are as follows; 1-If first drained bloody effusion exceeds $1500 \mathrm{ml}$ (more than $20 \mathrm{ml} / \mathrm{kg}$ ), 2-If drained bloody effusion exceeds $200 \mathrm{ml} / \mathrm{h}$ $(2 \mathrm{ml} / \mathrm{kg} / \mathrm{h})$ in the first $2-4$ hours or $100 \mathrm{ml} / \mathrm{h}$ in the first $6-8$ hours, 3-If patient's blood pressure decreases, the image of hemothorax on chest X-ray expands and if hemodynamic stability is not established despite i.v. volume replacement and drainage via chest tube, 4-If a diffuse opacity in the relevant hemithorax is detected on chest X-ray, 5-A continuing opacity on chest X-ray, suggesting that hemothorax is not adequately drained and that a thrombosed hemothorax formed. A thrombosed hemothorax must be sugically explored to prevent a fibrous shell formation and to decrease the risk of ampyema, 6-In case of hemopericardium or cardiac tamponade, 7-Injuries of aorta and great vessels. Video assisted thoracic surgery (VATS) was performed in cases who developed intrathoracic hematoma and could not be drained via chest tubes.

\section{Results}

The cause of hemothorax in our series was blunt trauma in 92 cases $(85.2 \%)$ and remaining 16 cases $(14.8 \%)$ were due to penetrating trauma. Etiologies causing hemothorax are shown in Table 1.

\begin{tabular}{lcc}
\multicolumn{2}{c}{ Table 1. Factors leading to hemothorax } \\
& $\mathbf{n}$ & $\mathbf{\%}$ \\
\hline Blunt trauma & 92 & 85.2 \\
Penetrating injury & 10 & 9.2 \\
Gunshot injury & 6 & 5.6 \\
Total & 108 & 100
\end{tabular}

While the most common cause of hemothorax in blunt trauma was traffic accident $(n=58,63.4 \%)$, in penetrating trauma it was penetrating injury $(n=10,62.55)$. Due to the fundament in our territory, roadway systems are increasingly preferred and that raises number of thoracic trauma cases resulting from roadways. Four cases were present in our series. 56 cases had other accompany organs injuries and fractures. Most common accompanying was extremity fractures in 24 cases $(22.2 \%)$ and second common fractures was at head. Accompanying injures and fractures are shown in Table 2.

Among hemothorax cases, 65 patients had also pneumothorax. In 15 cases of penetrating injury group (93.7\%) hemothorax was accompanied by pneumothorax while this rate in blunt trauma group was only $38.04 \%(n=35)$.

\begin{tabular}{lcc}
\multicolumn{2}{l}{ Table 2. Injuries accompanying hemothorax } \\
Injury & $\mathbf{n}$ & $\mathbf{0}$ \\
\hline Ekstremity fractures & 24 & 22.2 \\
Head trauma & 13 & 12.1 \\
Abdominal injury & 9 & 8.4 \\
Pelvic trauma & 6 & 5.6 \\
Vertebral fractures & 4 & 3.7 \\
Total & 56 & 52.0 \\
\hline
\end{tabular}

All cases with hemopneumothorax underwent tube thoracostomy. Thoracotomy was performed in 14 cases $(12.9 \%)$ and a patient with cardiac injury was operated via median sternotomy. As more than $1000 \mathrm{ml}$ drainage after tube thoracostomy was detected in 3 cases with thoracotomy and as it sustained, emergent thoracotomy was performed. Another emergent thoracotomy was carried out on bed when a patient developed a cardiac arrest after having a tube thoracostomy due to multiple rib fractures and hemopneumothorax. His thorax was surgically explored and spontaneous pulses were reestablished after internal cardiac compressions. He was transported to operation room for laparotomy. A ruptured spleen and diffuse intraabdominal bleeding was noted. He died on the fourth postoperative day. Another case with gunshot injury, weak cardiac pulses and unstable vital signs underwent an emergent thoracotomy in emergency unit conditions and he died due to hypovolemic shock. A patient with smashing type thoracic trauma, multiple rib fractures, flail chest, sternal fracture and bilateral hemopneumothorax died during the tube thoracostomy procedure due to cardiac trauma and hypovolemic shock. One of the cases followed up for an intracranial bleeding and hemothorax died on the seventh day of treatment. A patient with gunshot injury died on the following day due to intraabdominal organ and great vessel injury. Another patient with blunt thoracic trauma, multiple rib fractures and flail chest was entubated and died during the transport to an another intensive care unit. There were two cases with penetrating injury in our series, who had a right ventricular and a right atrial injury. An emergent right anterior thoracotomy was performed for the right ventricular injury case and an approximately $1 \mathrm{~cm}$ cut was repaired with pericardium as U-shaped. A patient with right parasternal penetrating injury had a tube thoracostomy and an immediate sternotomy using gigli wire was carried out as his drainage increased markedly. A cut of approximately $2 \mathrm{~cm}$ on right atrium was detected and primarily repaired. Both cardiac injury cases were transported to cardiovascular surgery centers in postoperative period. In their control visits there was no pathology except pain.Two cases diagnosed as late hemothorax underwent VATS. Most commonly injured intraabdominal organs were spleen and liver. Thoracotomy was performed in a total of 14 cases $(12.9 \%)$ and median sternotomy in only one case. During thoracotomies, pulmonary laceration was detected in 6 cases, cardiac injury in one case, intercostal arterial injury in 2 cases, parenchymal cut in 3 cases and diaphragmatic injury in 2 cases. Thoracotomy findings and treatment approaches are summarized in Table 3.

\begin{tabular}{lcc}
\multicolumn{2}{c}{ Table 3. Thoracotomy findings in hemothorax } \\
Thoracotomy findings & $\mathbf{n}$ & Treatment \\
\hline Parenchymal cut & 3 & Primary repair \\
Intercostal arterial injury & 2 & Ligation \\
Cardiac injury & 1 & Repair \\
Pulmonary laceration & 6 & Primary repair \\
Diaphragma injury & 2 & Primary repair \\
Total & 14 & \\
\hline
\end{tabular}

\section{Discussion}

Thoracic injuries are a major cause of mortality during the "golden hour" of trauma, as many patients with chest trauma die after reaching the hospital (Stahel et al., 2005). Thoracic 
trauma constitutes $25-50 \%$ of deaths due to trauma in all age groups (Hunt et al., 2006). Hemothorax is one of the most common pathologies encountered in blunt or penetrating thoracic trauma, which may require emergent thoracotomy and must be managed immediately (Battisella and Benfield, 2000). The most common cause of hemothorax in our cases was blunt thoracic trauma due to traffic accidents. Causes of hemothorax both in blunt and penetrating thoracic injuries may be lung parenchyma, all vascular structures in thorax, heart or abdominal organs with a ruptured diaphragma. It results most commonly from intercostal arteries, veins and lung parenchyma (Oğuzkaya, 2003). Blunt and penetrating thoracic trauma is commonly accompanied by organ injuries from other systems and thus, mortality and morbidity increase significantly (Leblebici et al., 2005). A multidisciplinary approach and treatment strategies are necesssary. In our series, 56 cases $(51.8 \%)$ with accompanying other organ injuries were revealed. Extremity fractures, head trauma, intraabdominal injury, pelvic and vertebral fractures were observed respectively. Respiration rate, arterial tension, skin appearance and cervical veins should be evaluated at first sight in trauma patients to decide their respiratory sufficiency and hemodynamics. If an effusion is identified on chest X-ray and thorax CT, first procedure to be planned is thoracentesis unless it is containdicated due to coagulopathy (Batırel and Yüksel, 2002). The first widely approved intervention in hemothorax treatment is tube thoracostomy. For an efficient drainage, the position of tube plays an important role as much as its diameter. To assess whether a chest tube provides sufficient drainage, drainage system must be monitored hourly and daily to reveal the total bleeding volume and daily chest $\mathrm{X}$-ray must be taken to compare reexpansion of lungs. Removal technique of chest tubes is also crucial. According to the literature there is an air intake during the expirium phase of respiration and therefore, tubes were taken off during the late phase of inspirium (Y1ldızeli and Yüksel, 2002). If adequate drainage is not achieved, fibrin deposits accumulate on the visceral pleura and causes pleural thickening and trapped lungs (IJpma et al., 2009). In a study all cases with hemothorax were drained via regular thoracentesis and no morbidity and mortality was observed in any patient (Cangir et al., 2000). However, ampyema due to residual hemothorax is a common late complication. Inadequately drained hemothorax leads to hematoma in thorax and trapped lungs. In 2 cases who developed hematoma in follow-up, VATS was performed in early stages to empty hematoma and complete expansion of lungs ensured. Emergency unit thoracotomy is known as a life saving intervention for a little subgroup of critical care patients. It was first performed by Moritz Schiff in 1874 for an open cardiac massage (Hunt et al., 2006). In our series a patient with gunshot injury underwent an emergency unit thoracotomy and died before maintaining hemostasis. Chest injuries constitute $10.4 \%$ of trauma cases necessitating surgical intervention and $1 \%$ of those are cardiac injuries, however, they cause $40 \%$ of deaths after chest injury (Oakland and Vivian, 1987; Ar1kan et al., 2003). The main goal in hemothorax cases is to evacuate the blood from the pleural space. When a tube is inadequate to drain, second or even a third tube may be placed (Coselli et al., 1984).

\section{Conclusion}

Hemothorax must be diagnosed urgently. Accompanying organ injuries and presence of a previous disease history affect the mortality. Cases admitted due to trauma must be absolutely consulted to relevant departments. Many potentially lifethreatening conditions can be relieved by simple procedures, such as chest tube insertion. Thoracotomy is also a life saving intervention in case of sustained hemorrhage and unstable hemodynamic conditions after tube thoracostomy.

\section{REFERENCES}

Akay, H., 2002. Approach to diagnosis and treatment of hemothorax. Turkish Respiratory Journal. 4, $195-205$.

Arıkan, S., Yücel, A.F., Kocakuşak, A., Dadük, Y., Adaş, G., Önal, M.A., 2003. Retrospective analysis of penetrating cardiac injuries. Turkish Journal of Trauma and Emergency Surgery. 9, 124-128.

Batırel, H.F, Yüksel, M., 2002. Evulation of Pleural Effusion: A Surgical Approach. Turkish Thoracic Journal. 3, 10-16.

Battisella, F.D., Benfield, J.R., 2000. Blunt and penetrating injuries of the chest wall, pleura and lungs. In shields TW, Lo cicero J 3rd, Ponn RB, editors. General thoracic surgery. 5 th ed. Philadelphia: Lippincott Williams\&Wilkins. 815-831.

Cangır, A.K., Nadir, A., Akal, M., Kutlay, H., Özdemir, N., Güngör, A., Kavukçu, Ş., Akay, H., Ökten, İ., Yavuzer, Ş. 2000. Thoracic trauma: Analysis of 532 cases. Turkish Journal of Trauma and Emergency Surgery. 6, 100-105.

Coselli, J.S., Mattox, K.L., Beall, A.C., 1984. Re-evaluation of early evacuation of clotted hemotorax. Am. J. Surg. 148, 785-790.

Hunt, P.A., Greaves, I., Owens, W.A., 2006. Emergency thoracotomy in thoracic trauma: A review. Injury. 37, 1-19.

IJpma, F.F., Van westreenen, H.L., Van Acker, G.J., 2009. Chest drains in trauma patients. Ned Tijdschr Geneeskd. $153: 300$.

Leblebici, H.I., Kaya, Y., Koçak, A.H., 2005. Analysis of 302 cases with thoracic trauma. Turkish Journal of Thoracic and Cardiovascular Surgery. 13, 392-396.

Oakland, C., Vivian J., 1987. Penetraring cardiac injuries. Br. Med. J. 295, 502-505.

Oğuzkaya, F., 2003. Traumatic hemothorax and pneumothorax. In Yuksel, M., Çetin, G., Thoracic trauma 1. Edition, İstanbul. Turgut Publishing, Inc.

Sayır, F., Çobanoğlu, U., Şehitoğulları, A., 2012. Traumatic hemothorax: Analysis of 282 patients. Turkish Thoracic Journal. 13 , 111-116.

Stahel, P.F., Schneider, P., Buhr, H.J., Kruschewski, M., 2005. Emergency Management of Thoracic Trauma, Orthopade. 34, 865-879.

Şentürk, E., Yoldaş, E., Doğan, Y., 2009. Management of hemothorax: An evaluation of 192 cases. Turkish Journal of Thoracic and Cardiovascular Surgery. 17, 92-96.

Y1ldıeli, B., Yüksel, M., 2002. Surgical techniques of pleural diseases. Turkish Thoracic Journal. 3, $27-41$. 